\title{
Assessment of Smoking Pattern among Patients Visiting a Private Dental Hospital in Chennai, India
}

\author{
Sonti Sri Harsha ${ }^{1}$, Dr. R. Pradeep Kumar ${ }^{2}$ \\ I (CRRI, Department of Public Health Dentistry, Saveetha Dental College, Saveetha University, India) \\ ${ }^{2}$ (M.D.S. M.Sc., Reader, Department of Public Health Dentistry, Saveetha Dental College, Saveetha University,
} India)

\begin{abstract}
The aim of the study is to evaluate the assessment of smoking pattern among 200 patients who are current smokers and have smoked tobacco in any form at any point of time during last month, with no history of trauma or mental disabilities, with the habit of smoking, who are randomly selected using a structured selfadministered questionnaire. From this study it was evident that more than 50\% of the population started smoking between 21-25 years of age. And more than 50\% of the smokers started smoking because of peer pressure, $33.5 \%$ due to stress and $13.5 \%$ responded that insomnia, social situation and nervousness/anxiety are factors which influenced them. The study also showed that although $72.5 \%$ of smokers showed interest to quit smoking, only $51 \%$ of them attempted to quit and $98.5 \%$ of them are not confident. To conclude, the present study reported the pattern of smoking in Chennai and a low success rate to quit smoking.. Hence improving the awareness about ill effects of smoking should be able to control tobacco epidemic.
\end{abstract}

Keywords: Cigarette, Habit, Smoking pattern, Tobacco.

\section{Introduction}

Today, around the world, tobacco is one of the most widely distributed and commonly used addictive substance $^{1}$. There are more than one billion smokers worldwide with nearly $80 \%$ of them living in low and middle income countries ${ }^{2}$.

Globally, around five million deaths every year are attributable to direct tobacco use, which is the largest preventable cause of death ${ }^{3}$. It has been estimated that there are more than 1.3 billion smokers worldwide, with around 84 percent residing in developing and transitional economy countries ${ }^{4}$. In India, among people aged 30 years and over, the mortality due to tobacco use is 206 per 1,00,000 in men and 13 per 1,00,000 in women with proportion of deaths attributable to tobacco reaching $12 \%$ for men and $1 \%$ for women ${ }^{3}$.

Tobacco is consumed in myriad forms in India which includes smoking as well as smokeless forms 5 . Smoking in most parts of India is reported in about one fourth to half of adult men over 15 years of age except in states like Punjab, Maharashtra and Sikkim ${ }^{5}$. Some street children and other homeless people in India spend more on tobacco than on food, education or savings ${ }^{6}$. Gajalakshmi GK et al (1997) reported that the highest rate of smoking is found among the illiterate population (64\%) in Chennai. This prevalence decreases by number of years of schooling, and it decreases to about one fifth (21\%) among those with more than 12 years of schooling ${ }^{7}$. Hence this study was designed to assess the smoking pattern among patients visiting a private dental hospital in Chennai, India.

\section{Materials and Methods}

The study population comprised of 200 patients with the habit of smoking, who are randomly selected. The ethical clearance was obtained from the institutional committee from Saveetha University, Chennai. Those participants who voluntarily consented for participation were subjected to in-depth interviews using structured questionnaire. The questionnaire was prepared after a detailed literature review followed by piloting of 30 subjects to check for feasibility and necessity of corrections. Data of subjects interviewed in the piloting stage were not included into the analysis. The inclusion criteria of the study group comprised of current smokers who have smoked tobacco in any form at any point of time during last month, with no history of trauma or mental disabilities.

The survey tool focused on assessing socio-demographic variables (age, gender) and their smoking pattern (Smoking initiation age, Number of years smoked, Number of cigarette's per day, Reason to start smoking, Money spent on smoking). Data was anonymously coded and entered into the spread sheet program and is subjected to analysis. 


\section{Results}

In this survey, we have included a total number of 200 male patients with a habit of smoking aged between 15 to 70 years. It was found that the number of cigarettes smoked ranged from 2 to 20 per day, on an average 6 cigarettes per day. It was evident that on an average Rs.27.90 is spent on smoking per day. It was also found that they also spent Rs.837.00 on smoking per month. Fig 1 shows number of cigarettes smoked per day among the study population. It was found that $63 \%$ of smokers use $1-5$ cigarettes per day. Fig 2 depicts age wise distribution of smokers in which, nearly half $(42 \%)$ of the study population represents $15-30$ years age. the study showed that the initiation age of smoking in which, it was found that more than $50 \%$ of the population started smoking between 21-25 years of age(Fig 3). It was found that more than 50\% of the population smoked for 1-15 years (Fig 4). It was noticed that more than 50\% of the smokers started smoking because of peer pressure, $33.5 \%$ due to stress and $13.5 \%$ responded that insomnia, social situation and nervousness/anxiety are factors which influenced them(Fig5). The study highlights, although $72.5 \%$ of smokers showed interest to quit smoking, only $51 \%$ of them attempted to quit and $98.5 \%$ of them are not confident (Fig 6).

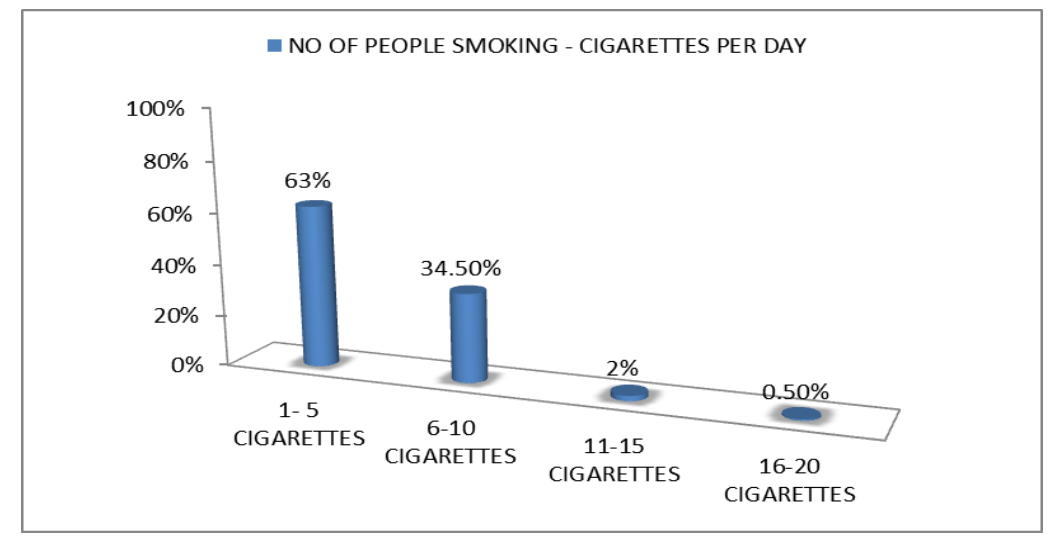

Figure 1: Distribution of smokers based on number of cigarettes smoked per day

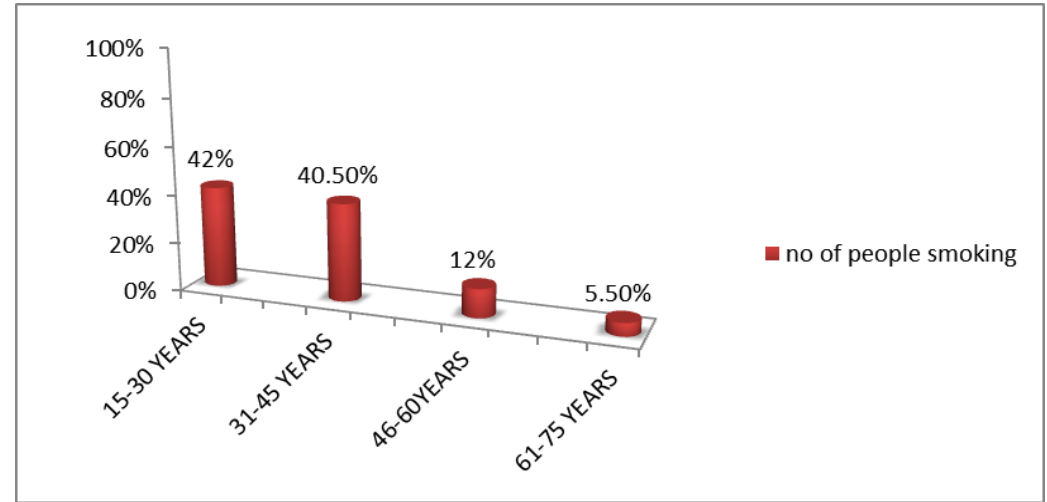

Figure 2: Age wise distribution of number of people smoking.

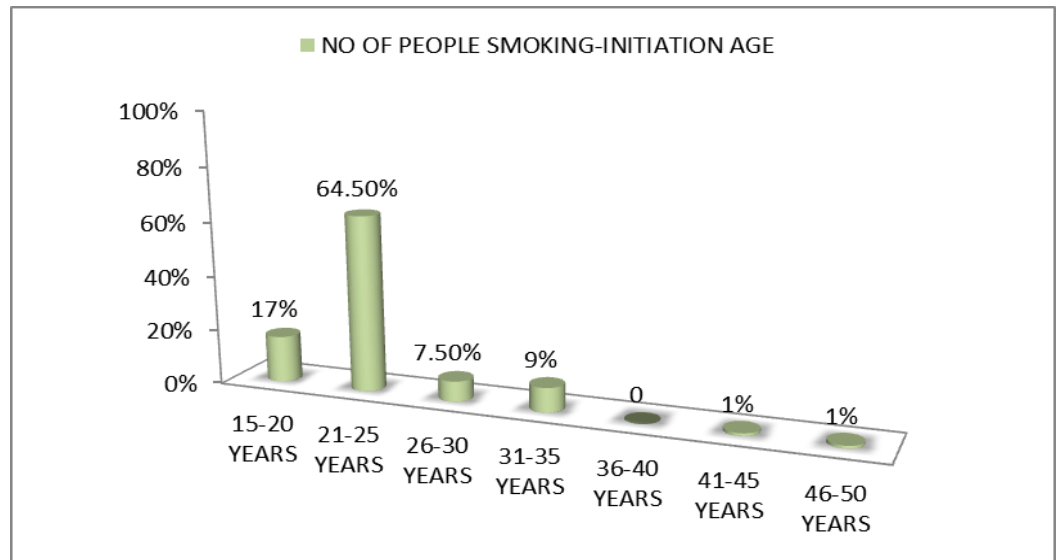

Figure 3: Distribution of smokers based on initiation age of smoking 


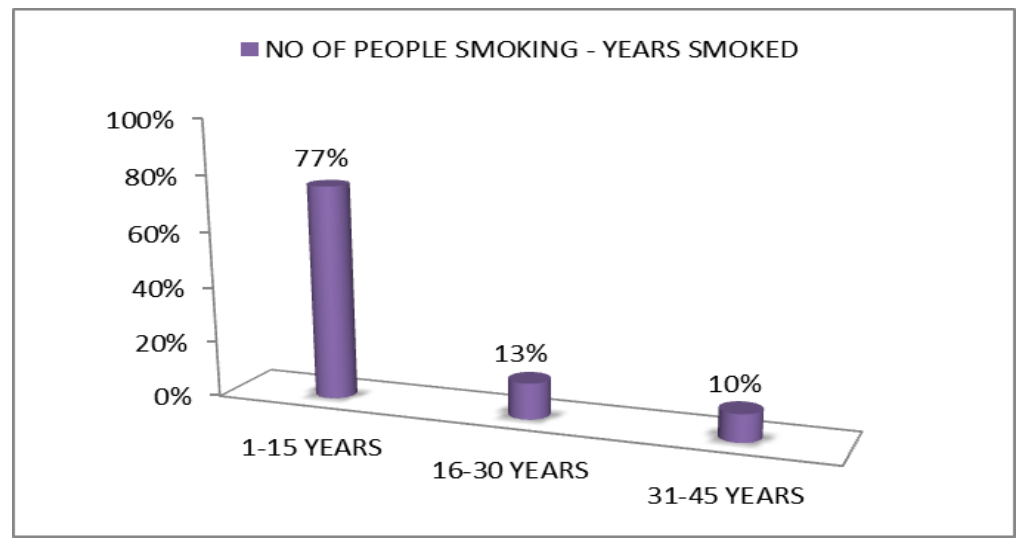

Figure 4: Distribution of smokers based on number of years smoked

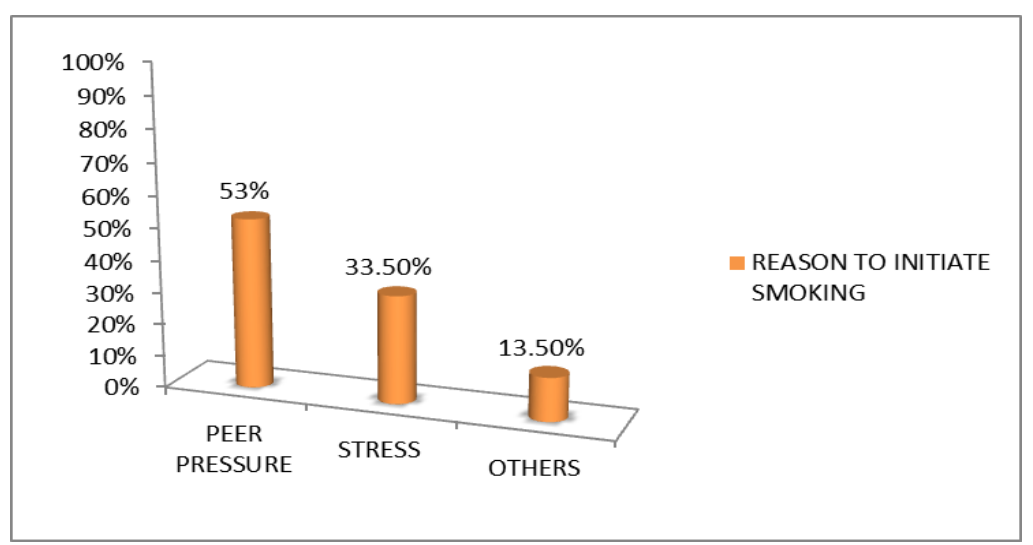

Figure 5: Reason to start smoking

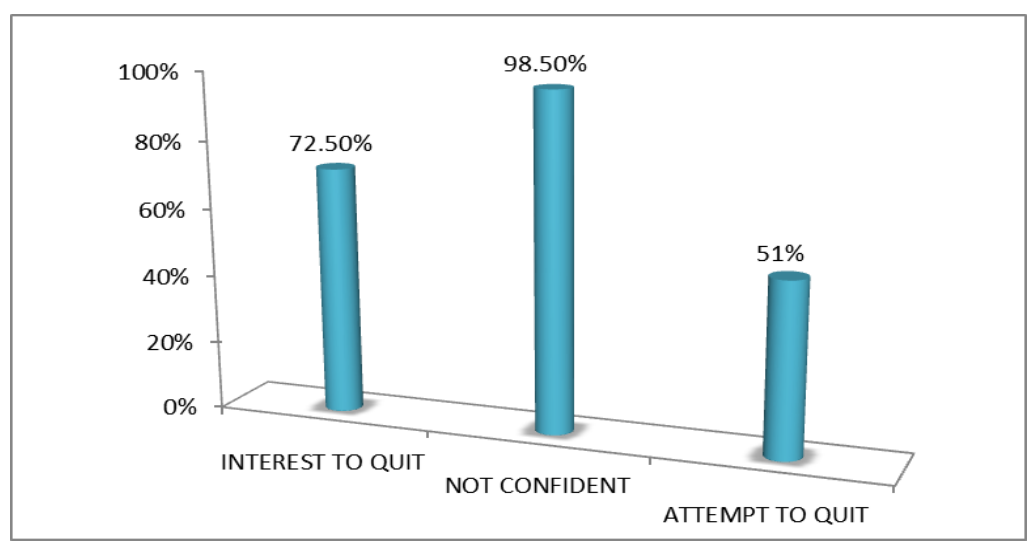

Figure 6: Smokers interest to quit, their confidence and attempt to quit smoking

\section{Discussion}

All 200 current smokers in the sample were males and $69.7 \%$ of them were either illiterate or educated up to primary level only. Majority of participants (79.6\%) in the study were laborers and semi-skilled workers. Bidi, the hand rolled form of tobacco, was used by $29 \%$ of the study population whereas S.K. Jindal et al 2005 reported that $51.7 \%$ of urban population use Bidi in Chandigarh ${ }^{8}$. Hookah smoking, the more traditional way is largely extinct in Chennai. The current smoking prevalence was highest among those aged 35-44 years (73\%) in a study conducted by Jean L. Forster et al in 2006 in Minnesota among American Indian population ${ }^{9}$ in contrast in this study $15-30$ years age group were the highest. Although almost all current smokers smoked every day, on an average they smoked about a half a pack of cigarettes per day which is similar to American Indian population in Minnesota. The average age at smoking initiation in Minnesota was 12.9 years, whereas it is 24.1 years in this study. 
Desai. K .T et al (2010) concluded that friends were first to introduce smoking (53.2\%) in Surat city ${ }^{10}$, which is similar to the present study. whereas Makwana et al (2007) showed that $61.69 \%$ of adolescent smokers have started tobacco smoking with friends in Jamnagar district, Gujarat state ${ }^{11}$. In Surat, the average amount spent on psychoactive substances used per month was found to be 348.5 Rupees ${ }^{10}$, whereas this study also provides insights about expenditure on tobacco that is Rs.837.00 spent per month, resulting in crowding out of expenditures on other needs. This finding is significant because it needs to be incorporated in the behavioral change counselling of smokers by explaining them their amount of spending and possible saving if they quit.

Jean L. Forster et al showed that $68 \%$ of current smokers would like to quit, and most of them $(53 \%$ of all smokers) had tried to quit in the previous 12 months ${ }^{9}, 64.6 \%$ smokers in Surat were not able to quit smoking $^{10}$. In this study $72.5 \%$ of smokers showed interest to quit smoking, $98.5 \%$ of them are not confident due to compulsive habit as the main reason for continuing smoking despite being aware of its dreadful consequences. Only $51 \%$ of them had past history of unsuccessful attempts to quit, which indicates their probable willingness to quit, but failure due to lack of proper guidance and support, which is an unmet demand for smoking cessation guidance.

\section{Conclusion}

To conclude, the present study reported the pattern of smoking in Chennai and a low success rate to quit smoking. Concerted efforts are needed to provide culturally appropriate smoking cessation information and assistance for this population. Hence improving the awareness about ill effects of smoking in India should be able to control oral cancer and lead to amelioration of the epidemic of life style diseases.

The study would have thrown more evident if components of awareness and opinions regarding Control of Tobacco Product Act (COTPA) had been included. In addition to the smoking pattern discussed above, economic burden of addiction is an important area to be discussed. Despite of certain limitations like small sample and lack of variance with respect to demographic variables due to entire population being from patients which smoking habit visiting a private dental hospital, in general the study adds important knowledge regarding tobacco epidemiology, as limited data is available from Chennai. But for the extrapolation of results to wider population and for policy decisions larger sample survey in the region needs to be carried out. Future research in the above mentioned direction should be carried forward to add new vistas.

\section{References}

[1] Makwana, N., Shah, V., \& Yadav, S. (2007). A study on prevalence of smoking and tobacco chewing among adolescents in rural areas of Jamnagar district, Gujarat state. Journal of Medical Sciences Research, 1(1), 47-50.

[2] World Health Organization. (2011). WHO report on global tobacco epidemic 2011: Warning about the dangers of tobacco (Report No. ISBN 978924 156426 7). Geneva, Switzerland: WHO.

[3] World Health Organization. (2012). WHO global report: Mortality attributable to tobacco (Report No. ISBN 9789241564434 ). Geneva, Switzerland: WHO.

[4] Guindon GE and Boisclair D. Past, Current and Future Trends in TobaccoUse. HNP Discussion paper, Economics of Tobacco Control Paper No.6.February 2003.

[5] Rani M, Bonu S, Jha P, Nguyen SN, Jamjoum L. Tobacco use in India: prevalence and predictors of smoking and chewing in a national cross-sectional household survey. Tobacco Control 2003; 12 : e4.

[6] Shah S, Vaite S. Choosing tobacco over food: daily struggles for existence among the street children of Mumbai, India, 2002; and PATH Canada and Shah S, Vaite S. Pavement dwellers in Mumbai, India: Prioritizing tobacco over basic needs. In: Efroymson D, ed. Tobacco and Poverty, Observations from India and Bangladesh, 2002.

[7] Gajalakshmi GK et al. Global Patterns of Smoking and Smoking-Attributable Mortality. Tobacco Control in Developing Countries. Oxford University Press, 2000.

[8] Jindal SK, Aggarwal AN, Chaudhry K, Chhabra SK, D'Souza GA, Katiyar SK, Kumar R, Shah B, Vijayan VK. Tobacco smoking in India; Prevalence, quit rates and respiratory morbidity. Ind I Chest Dis Allied Sci 2006; 48:37-42.

[9] Jean L. Forster, Kristine L. Rhodes, John Poupart, Lannesse O. Baker, and Cynthia Davey Patterns of Tobacco Use in a Sample of American Indians in Minneapolis-St. Paul Nicotine Tob Res (2007) 9 (Suppl 1): S29-S37 doi:10.1080/14622200601083434

[10] Desai, K. T., Gharat, V. V., Nayak, S. N., Patel, P. B., \& Bansal, R. (2012). Tobacco smoking patterns, awareness and expenditure: a crosssectional overview from Surat City, India. [Original study]. Tobacco Control and Public Health in Eastern Europe, 2(1), 25-32.

[11] Makwana, N., Shah, V., \& Yadav, S. (2007). A study on prevalence of smoking and tobacco chewing among adolescents in rural areas of Jamnagar district, Gujarat state. Journal of Medical Sciences Research, 1(1), 47-50. 